\title{
Structural and Photoluminescence Analysis on the Implantation of Carbon and Proton for the Creation of Damage-Assisted Emission in Silicon
}

(Struktur dan Analisis Fotoluminasi pada Penanaman Karbon dan Proton untuk Penghasilan Pelepasan KerosakanBerbantu dalam Silikon)

\author{
Nurul Ellena Abdul Razak, Morgan Madhuku, Ishaq Ahmad, Burhanuddin Yeop Majlis, Chang Fu \\ DeE \& Dilla DuRYha BerhanudDiN*
}

\begin{abstract}
We study the induced defects in the depth profiling of the silicon structure after being implanted with carbon and followed by high energy proton irradiation. It has been reported before that the formation of the optically active pointdefect, specifically the $G$-centre is due to the implantation and irradiation of carbon and proton, respectively. It is crucial to quantify the diffusional broadening of the implanted ion profile especially for proton irradiation process so that the radiation damage evolution can be maximized at the point-defect formation region. Profiling analysis was carried out using computational Stopping and Range of Ions in Matter (SRIM) and Surrey University Sputter Profile Resolution from Energy Deposition (SUSPRE) simulation. The energies of carbon ions adopted for this investigation are 10, 20, 30, and $50 \mathrm{keV}$, while proton irradiation energy was kept at $2 \mathrm{MeV}$. Photoluminescence measurements on silicon implanted with carbon at different energies were carried out to study the interrelation between the numbers of vacancies produced during the damage event and the peak emission intensities.
\end{abstract}

Keywords: Carbon; ion implantation; proton; silicon; SRIM

ABSTRAK

Kami melaporkan kecacatan dalam profil kedalaman struktur silikon selepas ditanamkan dengan karbon dan diikuti dengan penyinaran proton bertenaga tinggi. Sebelum ini telah dilaporkan bahawa pembentukan kecacatan titik berkeaktifan optik, khususnya pusat-G adalah disebabkan oleh implantasi karbon dan sinaran proton. Adalah penting untuk mengkuantifikasikan pelebaran profil implantasi ion terutamanya untuk proses penyinaran proton supaya evolusi kerosakan radiasi boleh dimaksimumkan di kawasan pembentukan titik kecacatan. Analisis profil dilakukan dengan menggunakan Perhitungan Pengiraan dan Julat Ion dalam Jisim (SRIM) dan simulasi SUSPRE. Tenaga ion karbon yang dikaji adalah 10, 20, 30, dan $50 \mathrm{keV}$, manakala tenaga penyinaran proton ditetapkan pada $2 \mathrm{MeV}$. Pengukuran fotoluminasi terhadap silikon yang telah ditanam dengan karbon pada tenaga yang berbeza dilakukan untuk mengkaji hubungan antara jumlah kekosongan yang dihasilkan semasa kejadian kerosakan dengan keamatan pelepasan.

Kata kunci: Ion implan; karbon; proton; silikon; SRIM

\section{INTRODUCTION}

Ion implantation is a valuable research and commercial tool to introduce dopants or radiation effects in materials. It has also been utilized in applications such as semiconductor device fabrication, materials synthesis and in advance materials research. The application of ion implantation particularly in device fabrication is to synthesize and modify the structural properties of the material. Recently, ion implantation technique has been used in the development of silicon light source in a bid to complete the integration of hybrid silicon electronics and optical system (Berhanuddin et al. 2019).

In this particular technique, ion implantation was used to implant carbon and irradiate proton to introduce optically active point-defect centres located near the surface of the silicon samples. This point-defect called the G-centre emits at telecommunication wavelength of $\sim 1.28 \mathrm{~mm}$ or $\mathrm{O}$ band (Berhanuddin et al. 2017). The centre comprises of one silicon interstitial and 2 carbon substitutionals, created by subsequent proton irradiation. Berhanuddin 
et al. (2012) have reported a double carbon implantation and proton irradiation technique to introduce the G-centre onto the silicon platform. The double implantations were carried out to form a flat carbon profile as well as to ensure a better uniformity of carbon concentration along the depth of samples (Berhanuddin et al. 2019, 2012). The proton irradiation process is crucial in this study as it will activate carbon complexes in the silicon lattice structure. Without proton irradiation, the G-centre will not be forming in the sample as the emissive G-centres are only found in the irradiated silicon (Berhanuddin et al. 2012; Rotem et al. 2007).

The formation of the G-centres or any other optically active point-defect centre is related to physical properties of dopants after the implantation process such as the ion spatial resolution, ion straggle, and ion channelling. Ion spatial resolution can be defined as the volume distribution and precision in the final position of implanted ions while ion straggle gives the physical intrinsic limit which can be achieved. Straggling occurs when implanted ions going through a series of multiple collisions with the incident atoms resulting in broadening in volume profile and uncertainties in final position of each implanted ion. Ion loses its energy while penetrating through substrate material and will eventually rest in their final position (Thabethe 2014). Ion channelling is the path of the ion that penetrates into the sample which is influenced by the crystal lattice structure (Alford 2007). This path is the result from the scattering between ions and atoms bordering the channel (Thabethe 2014). This ion channeling reduced the backscattering occurrence (Husnain et al. 2012) and can affect the range distributions of the implanted ions in the sample.

Therefore, it is crucial to study the spatial resolution, ion straggling, and ion channelling of the implanted ion. There are few implant models to simulate ion implantation such as Gaussion Implant Model, Pearson Implant Model, Dual Pearson Model, and Monte Carlo Implant Model. Among the implant models, Monte Carlo Implant Model is the most flexible and universal to simulate ion implantation with high accuracy (Jahanshah et al. 2007). The spatial resolution, ion straggling, and ion channeling can be simulated by using Stopping and Range of Ions in Matter (SRIM) which is based on the Monte Carlo Implant Model. We used it to calculate the ion deposition profiles in materials that are exposed to energetic ion beams (Gibbons 1972; Stoller et al. 2013). Other simulation software used in this manuscript is Surrey University Sputter Profile Resolution from Energy Deposition (SUSPRE) (Webb 2001). It is a quick ion implantation calculator that can calculate the energy deposited by ions (Biersack 1981; Gibbons 1972). By using SRIM and SUSPRE simulations, the profile damage in the silicon can be studied.
Damage profiling is crucial to quantify the defect production after the carbon and proton implantation. It is also used to estimate the number of ion vacancies produce after the collisions events. The analysis will also give the straggling and distribution profiles at particular implantation energy. In this work, the energy of carbon ions is varied to study the effect of different implantation energy to the damage and vacancies produced in the silicon samples. Finally, photoluminescence (PL) measurements were carried out on samples implanted with carbon at cryogenic temperature to study the relation between the numbers of vacancies created after the damage events with the emission intensities from silicon.

\section{MATERIALS AND METHOdS \\ DAMAGE ANALYSIS BY SRIM}

SRIM simulation can be used to understand the properties and interactions of ions with matter (Schmidt 2017). This simulation was utilized to study the spatial resolution, ion straggling, and ion channelling during and after the implantation. Silicon was selected as the target layer while carbon was defined as implanted ion with angle of deposition set at $7^{\circ}$ in accordance to previous report to minimize the effect of ion channelling (Buckley 2020; Thabethe 2014).

Carbon ion was chosen to be deposited into silicon wafer specifically to introduce the optically active pointdefect, such as the G-centre which is formed when silicon interstitial interacted with carbon substitutional-carbon interstitial (CsCi) complex (Berhanuddin et al. 2019). It is also necessary to increase the amount of substitutional carbon to increase the number of point-defect complex in the silicon samples (Rotem et al. 2007). At each simulation, the carbon ions are implanted twice on the silicon target to achieve a uniform carbon distribution along the depth of silicon.

The width of the target was set at $300 \mathrm{~nm}$, maximum depth at around $250 \mathrm{~nm}$ and the total number of ion was set at 1000 .

The first set of simulation, set A, was implanted with $30 \mathrm{keV}$ of carbon ions. The second simulation, set $\mathrm{B}$ was implanted with $30 \mathrm{keV}$ of carbon ions and followed by $10 \mathrm{keV}$ for second implant to follow the implantation parameters from previous study (Berhanuddin et al. 2012). The final set of simulation, set $\mathrm{C}$ was first implanted with $50 \mathrm{keV}$ of carbon ion and followed by $20 \mathrm{keV}$ for second implant. For set B and C, the carbon ions were implanted twice on the silicon target to achieve a uniform carbon distribution along the depth of silicon. The ion distribution and vacancies were then recorded and investigated. All sets were further irradiated with proton with high energy of $2 \mathrm{MeV}$. Details of the SRIM simulation of carbon implantation energy were given in Table 1. 
The simulation for all three sets was repeated by using SUSPRE software to compare the accuracy of each simulation tool. However, in SUSPRE interface, the doses of carbon ions need to be specified. Therefore, the dose for set $\mathrm{A}$ is defined at $4 \times 10^{13} \mathrm{~cm}^{-2}$. For set $\mathrm{B}$ and
$\mathrm{C}$, the doses are $4 \times 10^{13} \mathrm{~cm}^{-2}$ for the first implant and $1.1 \times 10^{13} \mathrm{~cm}^{-2}$ for the second implant. Decision on the doses of carbon was made by referring to the optimized parameters of carbon implantation from previous report (Berhanuddin et al. 2019).

TABLE 1. Carbon implant energy for each set of simulation using SRIM software

\begin{tabular}{ccc}
\hline & \multicolumn{2}{c}{ Carbon implant $(\mathrm{keV})$} \\
\cline { 2 - 3 } Set & $1^{\text {st }}$ implant & $2^{\text {nd }}$ implant \\
A & 30 & - \\
B & 30 & 10 \\
C & 50 & 20 \\
\hline
\end{tabular}

\section{PHOTOLUMINESCENCE MEASUREMENTS}

$\mathrm{N}$-type silicon wafers (100) with thickness of $525 \mu \mathrm{m}$ were implanted with carbon at different energies with the details as shown in Table 2. All of the implantation parameters for sample $\mathrm{A}, \mathrm{B}$, and $\mathrm{C}$ were chosen to be the same as parameters from the SRIM and SUSPRE simulations with the exclusion of proton irradiation.

TABLE 2. Sample details. All samples were implanted with carbon at different energies ranging from 10 to $50 \mathrm{keV}$. Sample A was implanted with carbon at $30 \mathrm{keV}$ while sample $\mathrm{B}$ and $\mathrm{C}$ were double implanted with carbon at $30 / 10 \mathrm{keV}$ and $50 / 20 \mathrm{keV}$, respectively. The average carbon volume concentration was calculated using SUSPRE (Webb 2001)

\begin{tabular}{|c|c|c|c|c|c|}
\hline \multirow[b]{2}{*}{ Set } & \multicolumn{2}{|c|}{$1^{\text {st }}$ implant } & \multicolumn{2}{|c|}{$2^{\text {nd }}$ implant } & \multirow{2}{*}{$\begin{array}{c}\text { Carbon volume } \\
\text { concentration }\left(\mathrm{cm}^{-3}\right)\end{array}$} \\
\hline & $\begin{array}{l}\text { Energy } \\
(\mathrm{keV})\end{array}$ & $\begin{array}{c}\text { Dose } \\
\left(\text { ion } \mathrm{cm}^{-2} \text { ) }\right.\end{array}$ & $\begin{array}{l}\text { Energy } \\
(\mathrm{keV})\end{array}$ & $\begin{array}{c}\text { Dose } \\
\text { (ion } \mathrm{cm}^{-2} \text { ) }\end{array}$ & \\
\hline A & 30 & $4 \times 10^{13}$ & - & - & $4 \times 10^{18}$ \\
\hline B & 30 & $4 \times 10^{13}$ & 10 & $1.1 \times 10^{13}$ & $4 \times 10^{18}$ \\
\hline $\mathrm{C}$ & 50 & $4 \times 10^{13}$ & 20 & $1.1 \times 10^{13}$ & $3 \times 10^{18}$ \\
\hline
\end{tabular}

Photoluminescence (PL) measurements were performed at temperature of $80 \mathrm{~K}$ across the $1.0-1.4 \mu \mathrm{m}$ spectral region with samples mounted in a continuous-flow helium cryostat. The PL was excited by a laser at $532 \mathrm{~nm}$ at a power density of $\sim 200 \mathrm{~mW} \mathrm{~mm}^{-2}$. The emission was detected by a cooled InGaAs photodiode and process by a lock-in amplifier. 


\section{RESULTS AND DISCUSSION}

The effect of lateral broadening and ion straggling can be observed and investigated in the SRIM simulation profile. Figure 1 shows the SRIM simulation for set A when carbon ions were set at energy of $30 \mathrm{keV}$. Defects were created along the whole ion trajectory, mainly interstitials and vacancies. At energy of $30 \mathrm{keV}$, most of the distributed ions concentrated at around $100 \mathrm{~nm}$ depth. Figure 1(a) shows the carbon profile of set A.
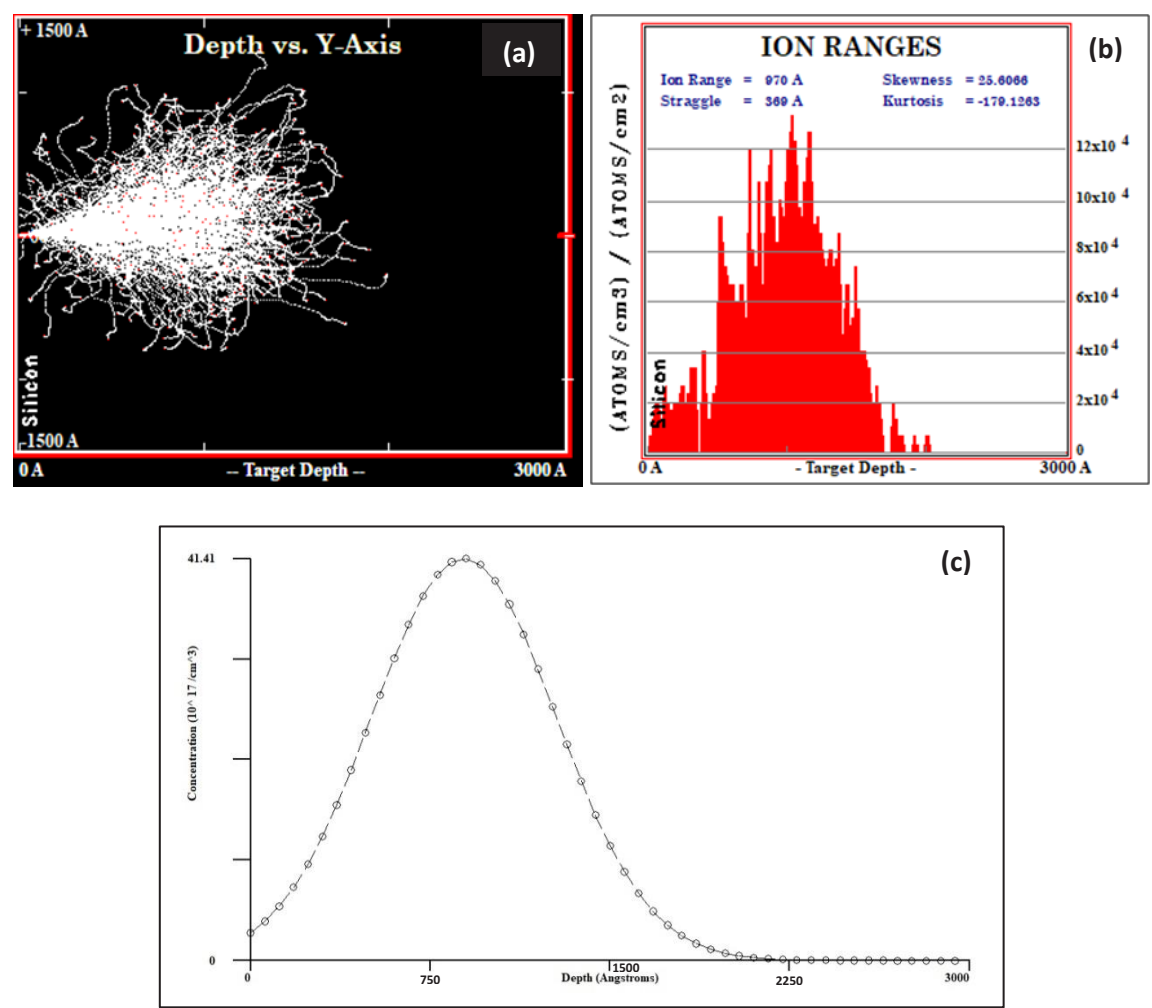

FIGURE 1. SRIM simulation result for set A with $30 \mathrm{keV}$ of carbon implant showing

(a) the carbon profile and (b) the distribution of damage in silicon. (c) is the SUSPRE simulation graph for set A showing the carbon concentration of $4 \times 10^{18} \mathrm{~cm}^{-3}$.

The volume concentration of the carbon ions from SRIM can be calculated using the following formula;

$$
\text { Value }\left(\text { atoms } \mathrm{cm}^{-1}\right)=\frac{\text { Volume }\left(\text { atoms } \mathrm{cm}^{-3}\right)}{\text { Dose }\left(\text { atoms } \mathrm{cm}^{-2}\right)}
$$

The range is the total distance where the ion concentration is at the highest which corresponds to the highest peak. From this set, the ion range is $\sim 97 \mathrm{~nm}$ with value of the actual peak (without noise) is $10 \times 10^{4}$ atoms $\mathrm{cm}^{-1}$ as shown in Figure 1(b). By referring to Figure 1(b) on the highest peak, the volume of the carbon ions is calculated to be $4 \times 10^{18}$ atoms cm-3 with $4 \times 10^{13} \mathrm{~cm}^{-3}$ dose of the carbon ions as stated in Table 2. The volume concentration calculated from SRIM agrees with result obtain from SUSPRE. As expected, the depth of implanted ions from SUSPRE is the same as the depth from Figure 1(a) which is at around $150 \mathrm{~nm}$. From Figure 1(c), the SUSPRE result matches with the lateral broadening distribution as shown in Figure 1(b).

Figure 2(a) shows the ion distribution for set B with first carbon implantation of $30 \mathrm{keV}$ and second implantation of $10 \mathrm{keV}$. The depth of the ions is similar with set A with the difference of ion distribution at near the surface of silicon. The carbon ions distribution is more uniform along the channelling depth as soon as it penetrates the sample. The consistency is due to the low energy of the second implantation which is at $10 \mathrm{keV}$. The high energy ions can penetrate deeper into the sample while ions with low energy only distributed especially laterally 

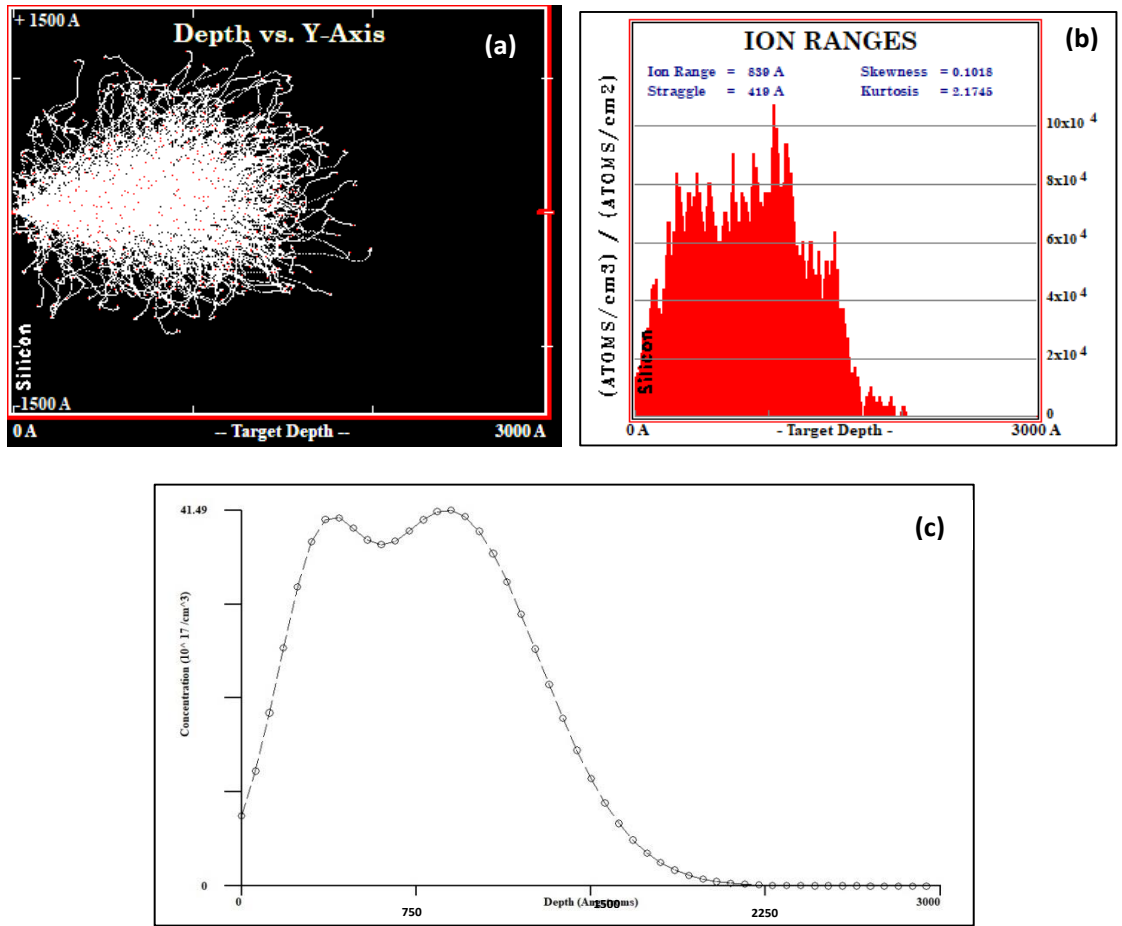

FIGURE 2. SRIM simulation result for set B with $30 / 10 \mathrm{keV}$ of carbon double implant showing (a) the carbon profile and (b) the distribution of damage in the silicon. (c) is the SUSPRE simulation graph for set B showing the carbon concentration is $4 \times 10^{18} \mathrm{~cm}^{-3}$

near the surface of silicon lattice. Figure 2(b) shows that there are two peaks at $\sim 50$ and $100 \mathrm{~nm}$ where the carbon ions are concentrated that correspond to the double implantation of carbons. The highest peak has a value of $8 \times 10^{4} \mathrm{~cm}^{-1}$ with volume concentration of $4 \times 10^{18} \mathrm{~cm}^{-3}$.
The double implantation gives a better result with an almost flat graph on SUSPRE. This SUSPRE result agrees with SRIM result as the depth and lateral broadening distribution of both results are similar.
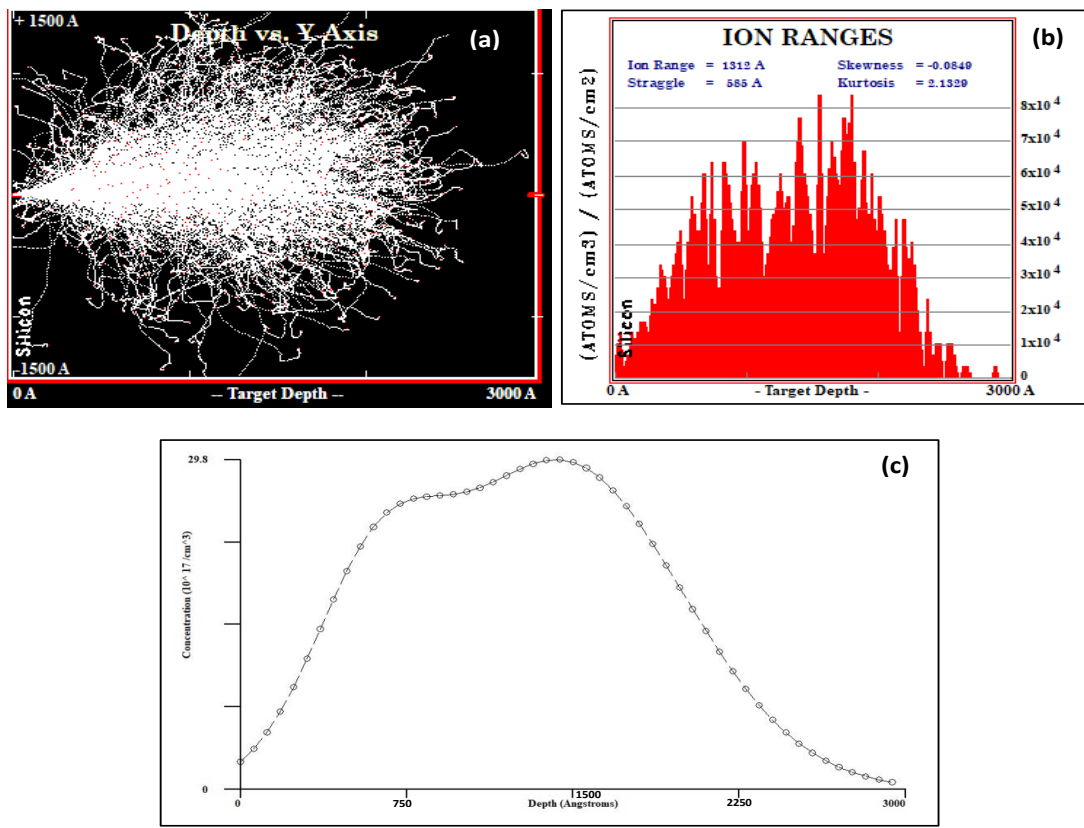

FIGURE 3. SRIM simulation result for set $\mathrm{C}$ with $50 / 20 \mathrm{keV}$ of carbon double implant showing (a) the carbon profile and (b) the distribution of damage in the silicon. (c) is the SUSPRE simulation graph for set A showing the carbon concentration is $2.9 \times 10^{18} \mathrm{~cm}^{-3}$ 
Figure 3(a) shows the ion distribution of set C. As predicted, this set produced the highest damage as the ions are able to scatter and penetrate deeper into the silicon lattice. The ions penetrate up to $200 \mathrm{~nm}$ in depth and spread up to $300 \mathrm{~nm}$ wide. The high depth and width of penetration are due to the high incident energies. This set is bombarded with $50 \mathrm{keV}$ for the first implantation and $20 \mathrm{keV}$ for second implantation. This set has also created the highest damage among others. For set A and B, the ions are distributed within $75 \mathrm{~nm}$ wide and $20 \mathrm{~nm}$ depth which are smaller area compared to set $\mathrm{C}$ where ions are distributed within $200 \mathrm{~nm}$ wide and $300 \mathrm{~nm}$ depth. Set C shows a high ion ranges at $\sim 131 \mathrm{~nm}$. This shows that most of the ions are found to be concentrated at $\sim 131 \mathrm{~nm}$ from the surface after being implanted at an energy of $50 \mathrm{keV}$. Figure $3(\mathrm{~b})$ shows the peak profile value of $6 \times 10^{4} \mathrm{~cm}^{-1}$ with volume concentration of $3 \times 10^{18} \mathrm{~cm}^{-3}$ as calculated by using (1). As the set is bombarded with two different energies, it produced bigger damage area with higher range as the ions do not accumulate at just one point. Set $\mathrm{C}$ produced the biggest range and the largest area among the other sets. Due to this, it can be deduced that set $\mathrm{C}$ produced the highest vacancies in silicon. Production of vacancies is crucial in order to create the optically active point-defect centres or any damage-induces centres that contribute to emission in silicon. From Figure 3(c), set C has produced a more uniform carbon profile, with a higher lateral broadening distribution attributed to the double implantation.
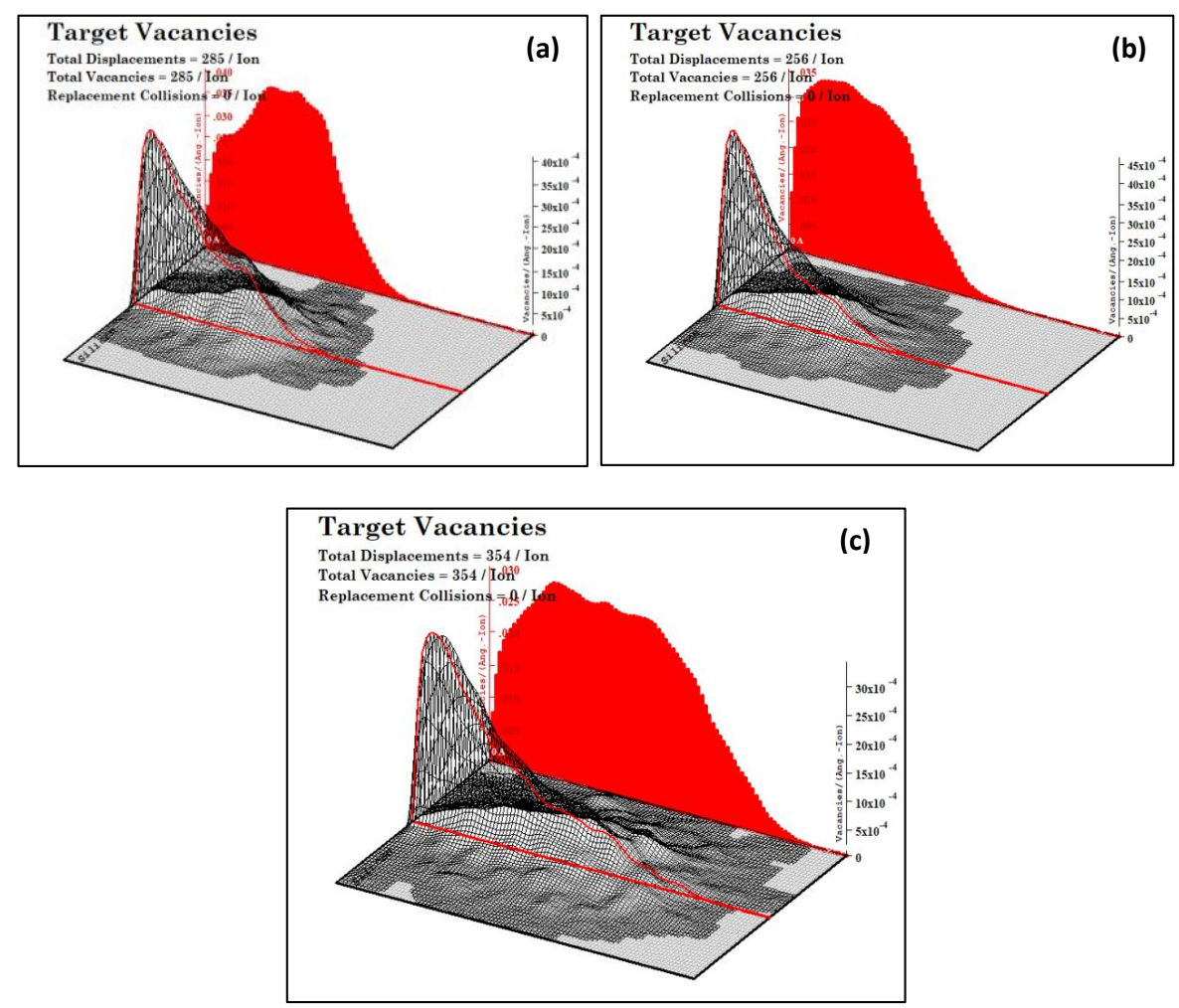

FIGURE 4. The target vacancies are 285, 256, and 354 ions for (a) Set A, (b) Set $\mathrm{B}$, and (c) Set C, respectively. The highest vacancies are 354 ions from set $\mathrm{C}$ while the lowest are 256 ions from set B

Figure 4 shows the total displacements and number of vacancies produced by each set. As stated before, the number of vacancies produced is important in order to create the point-defect or damage centres that contributed to the emission from silicon. By creating the vacancies in the silicon lattice, more carbon ions can reside in the lattice, thus creating more substitutional and interstitial ions which form variety of optically active point-defect centres such as the G-centre, C-centre, and $\mathrm{W}$ centre (Davies 1989). The total displacement or total vacancies for set A, B, and C are 285, 256, and 354, respectively. As expected, set $\mathrm{C}$ with implantation energies of 50 and 
$20 \mathrm{keV}$ produces highest number of vacancies. However, excess interstitials created due to high number of vacancies might accumulate with each other, thus causing the formation of passive defect on the lattice which will lower the number of the optically active point-defect complexes. Therefore, it is crucial to determine the optimize value of the implantation energy in order to get highest emission from the silicon by studying the photoluminescence (PL) spectrum.

The purpose of proton irradiation is to activate the formation of point-defect centres in the silicon lattice. Without the proton irradiation, ions do not move and will only accumulate and become saturated. There are two effects of the proton irradiation. First, the high energy proton will form interstitial defect by breaking the bonds in the lattice, thus, the ions in the sample are activated. Second, the proton will penetrate the sample without collision if the lateral distance of the material is short enough exemplarily a nanowire (Dee et al. 2011).
However, the latter is not the case in this study. A higher proton irradiation will reduce the chances of formation of the optically active point-defect centres due to the excess of self-interstitials that form another type of non-radiative damage centres (Berhanuddin et al. 2012).

Figure 5 shows the SRIM simulation results for the carbon implant profile after irradiated with $2 \mathrm{MeV}$ of proton for set $\mathrm{A}, \mathrm{B}$, and $\mathrm{C}$. The ion distribution and ranges of the samples remain the same with or without the proton irradiation as the irradiation will only effect and activated the interstitials and substitutional ions. Due to that, the number of vacancies within the silicon lattice will change after the high energy proton bombardment as shown in Figure 6. After the samples were irradiated with proton, the number of vacancies reduced as this is the actual number of silicon interstitial produced. At this point, the silicon ions had moved out from their lattice sites and become silicon interstitials. This is also the number of carbon ions that can move into the lattice to become substitutional carbon.
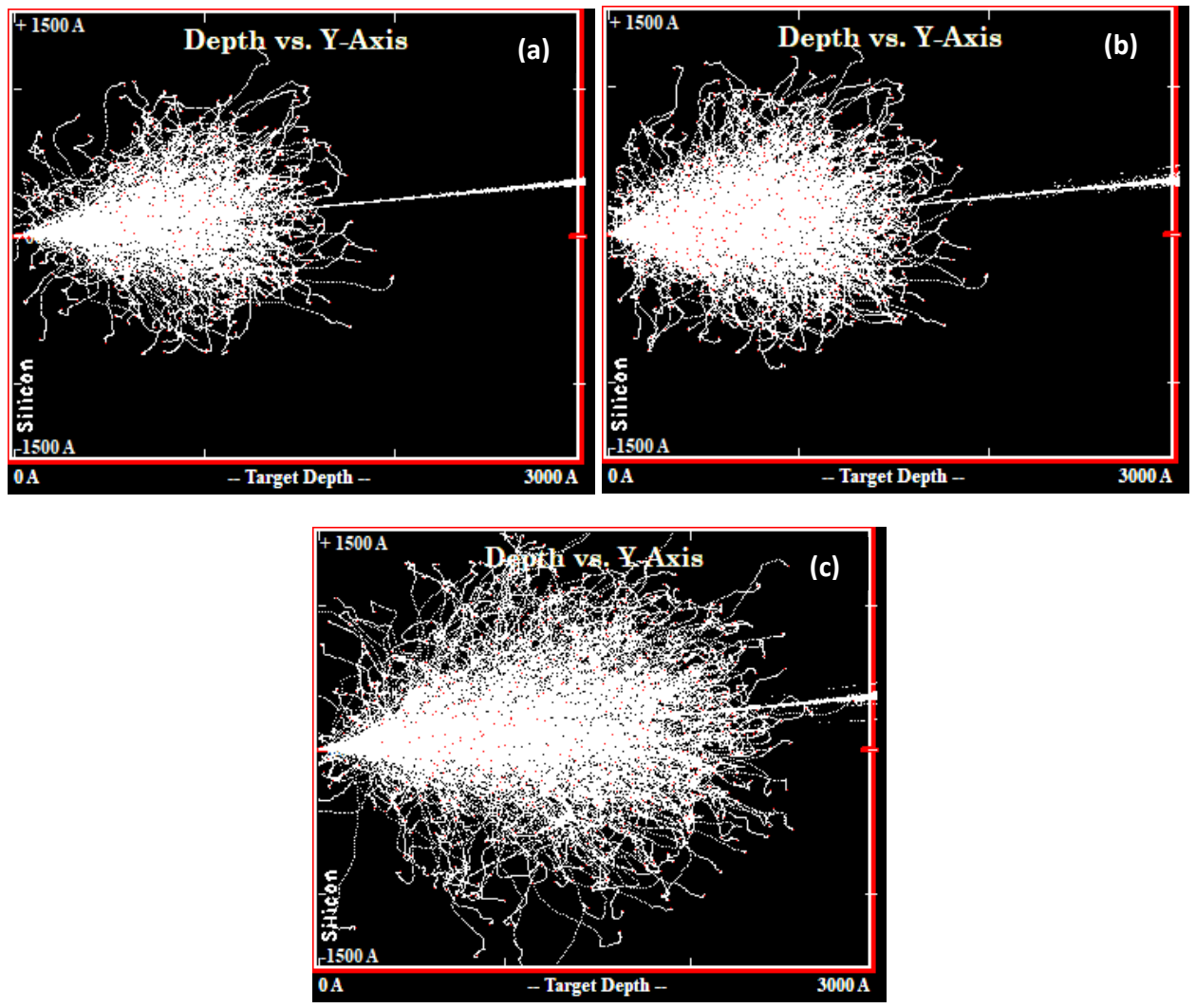

FIGURE 5. SRIM simulation result for the carbon implant profile after irradiated with 2 $\mathrm{MeV}$ of proton for (a) Set A with $30 \mathrm{keV}$ (b) Set B with $30 / 10 \mathrm{keV}$, and (c) Set C with $50 / 20 \mathrm{keV}$ of carbon implant 
The distribution of carbon ions does not significantly change with or without the proton irradiation. As mentioned earlier, protons pass through the damage done by carbon ions and accumulated at the back of the sample due to the very high energy of irradiation. The depth and lateral broadening profile of the silicon lattice remain similar to before the irradiation.
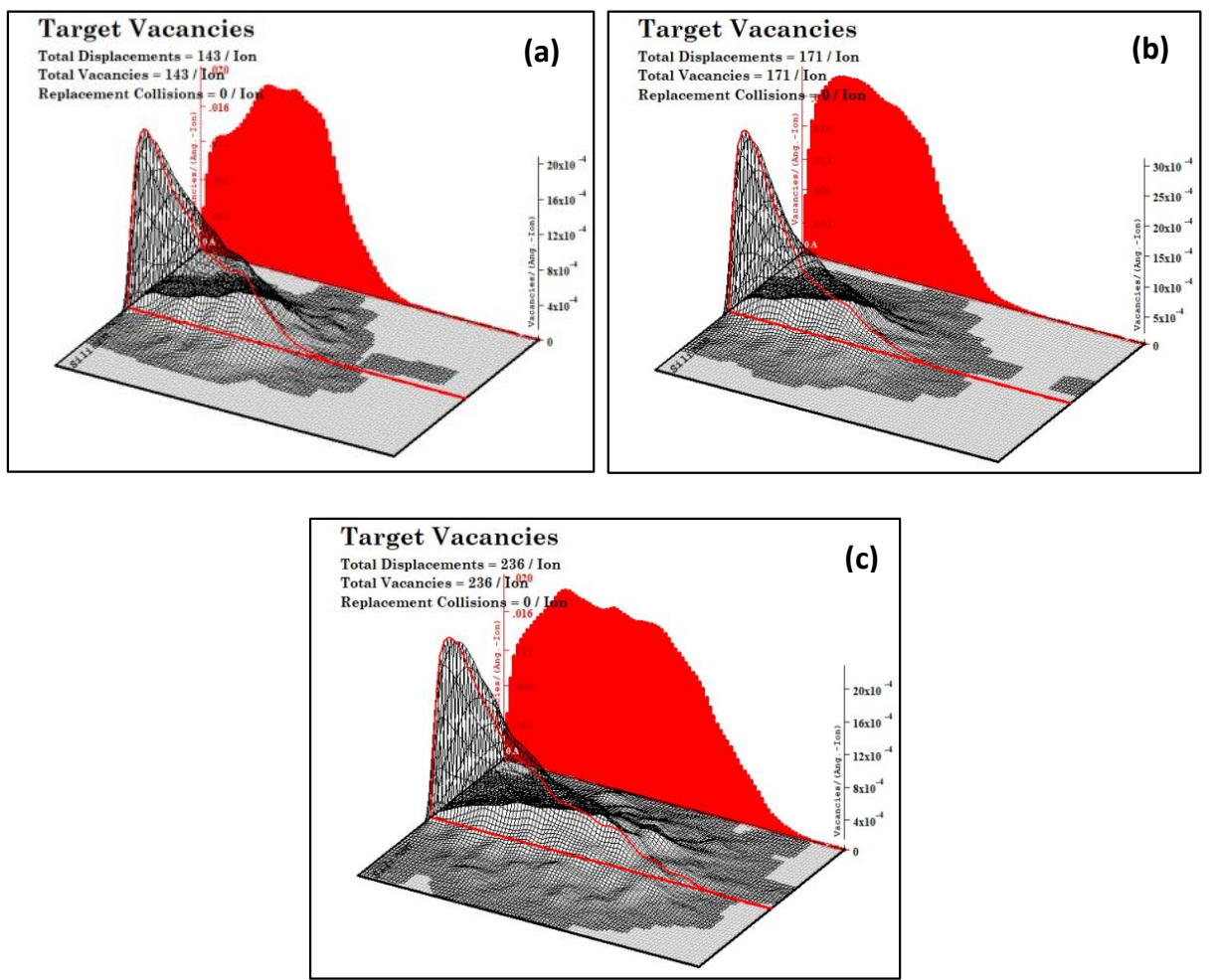

FIGURE 6 . The target vacancies after irradiated with $2 \mathrm{MeV}$ of proton are 142 , 171, and 236 ions for (a) Set A, (b) Set B, and (c) Set C, respectively. The highest vacancies are 236 ions from set $\mathrm{C}$

Figure 6 shows that the total vacancies have been reduced to 143 ions for set $\mathrm{A}$ (Figure 6(a)), 171 ions for set $\mathrm{B}$ (Figure 6(b)) and 236 ions for set $\mathrm{C}$ (Figure 6(c)). The reduction in total vacancies after proton irradiation is due to the movement of interstitials into the substitutional sites. Some of the substitutional and interstitial ions may also have complex with each other forming various damage and point defect centres as reported by Berhanuddin et al. (2012) where excess silicon interstitials will accumulate and form clusters with each other. Set $\mathrm{C}$ has produced the highest number of vacancies as it produced a deeper and wider carbon ion distribution in the silicon sample while Set A has the lowest number of vacancies after the irradiation. However, set $\mathrm{C}$ may also promote more passive defects compared to others due to possibility of all the excess interstitials aggregating with each other and becoming less mobile. It is expected that the excess interstitials will be trapped in the clusters that prevent it from forming silicon-interstitial related defects (Charnvanichborikarn et al. 2010). This will be confirmed by carrying out the PL characterization of silicon samples.

Figure 7 shows the PL spectrum for set A, set B, and set $\mathrm{C}$ at $80 \mathrm{~K}$ for the real samples implanted with carbon with energy as stated in Table 2. Two distinct peaks can be observed in the PL spectrum. According to Nguyen et al. (2016), the first peak at $1112 \mathrm{~nm}$ is the band-to-band emission from the silicon substrate while the second peak at $1170 \mathrm{~nm}$ is the band-to-band emission due to heavily doped layer near the surface. The peak at $1170 \mathrm{~nm}$ is present in all three samples with the highest intensity being observed in sample B. 


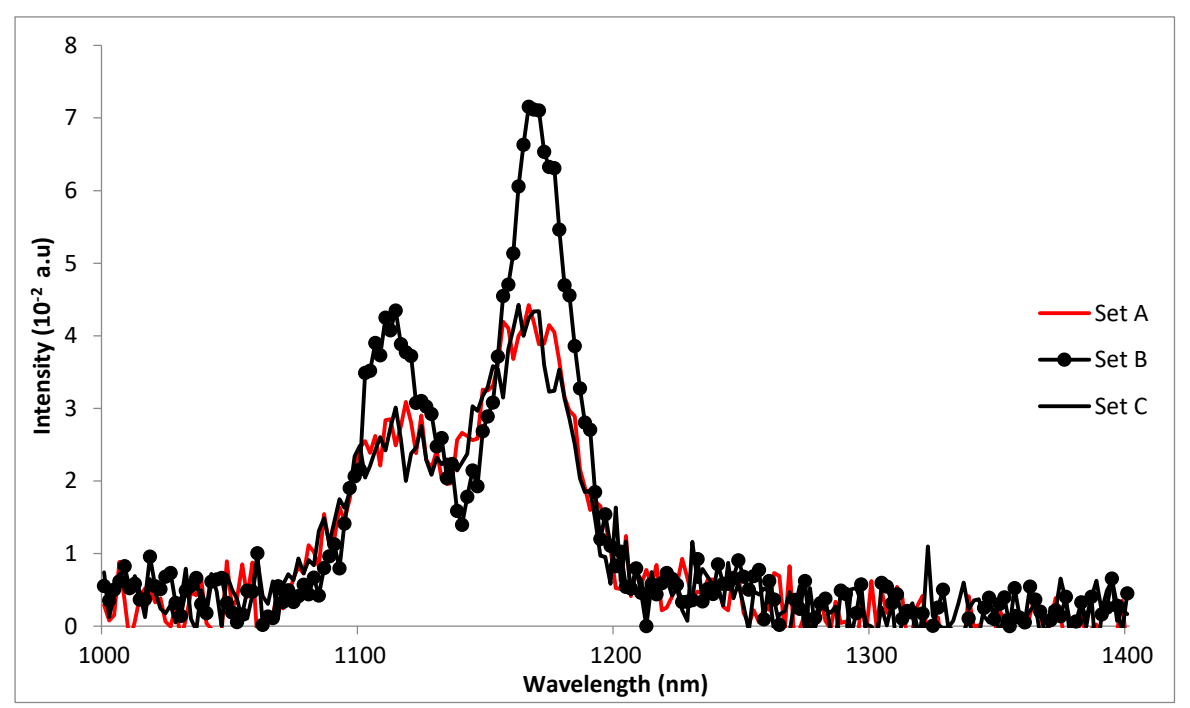

FIGURE 7. Photoluminescence analysis for sample A, sample B and sample $\mathrm{C}$ at $80 \mathrm{~K}$. Sample B shows the highest peak luminescence intensity with double carbon implantation of 30 and $10 \mathrm{keV}$

Based on this PL spectrum, sample B gives the highest luminescence intensity compared to sample $A$ and sample B. This result shows that sample B with double implantations of 30 and $10 \mathrm{keV}$ is the best combination to improve the emission property in silicon. The double implantations give a higher peak luminescence compared to the sample with single implantation. Berhanuddin et al. (2012) stated that double implantations process is crucial to ensure a better uniformity of carbon concentration in the sample. Despite the highest number of vacancies in set $C$, it will also lead to the segregation of carriers thus resulting in a lower formation of the active interstitials. This is proven by Berhanuddin et al. (2012) that by implanting higher doses of carbon will decrease the formation probability of the optically active G-centre due to the accumulation of excess silicon interstitials that form other radiative and non-radiative centres.

\section{CONCLUSION}

In summary, we have demonstrated and investigated the formation of vacancies that contribute to the number of substitutional and interstitial ions in the silicon lattice. These are crucial in order to determine their role in assisting and improving the luminescence in silicon. The SRIM and SUSPRE simulation results are similar, thus proving the profile of the ions after implanted in the silicon. Set B produced a better lateral broadening distribution as ions are distributed evenly near the surface with ion range of $\sim 84 \mathrm{~nm}$ which is the lowest value compared to set $\mathrm{A}$ and $\mathrm{C}$. By looking at the vacancies number both after carbon implantation and proton irradiation, set $\mathrm{C}$ produced the highest vacancies among the sets while set $\mathrm{B}$ producing the lowest. This situation can be described by observing the photoluminescence spectrum of all sets. We suggest that the highest intensity observed in set $\mathrm{B}$ is due to the fact that the ion range of set $B$ is the nearest to the surface. This will increase the probability of radiative recombination due to the absorption of light is more efficient near the surface. Despite the higher number of vacancies produced in set $\mathrm{A}$ and $\mathrm{C}$, they will result in excess interstitials in the lattice which will likely to aggregate with each other and not assisting in improving the emission in silicon. We suggest the optimum parameter for samples that gives the highest luminescence intensity is set $\mathrm{B}$ which is the double implantation of carbon ion with energy of $30 \mathrm{keV}$ and $10 \mathrm{keV}$. The next step is to improve the luminescence in silicon to emit light even at the room temperature.

\section{ACKNOWLEDGEMENTS}

The findings within this paper were previously presented at The NanoMITe Annual Symposium \& Nanotechnology Malaysia Annual Symposium (NanoSym), Putrajaya, 2019. The authors would like to acknowledge the Ministry of Education, Malaysia for financial support under the Fundamental Research Grant Scheme FRGS/1/2018/STG07/UKM/02/15. The authors also acknowledge the financial support under Universiti Kebangsaan Malaysia, Grant PP-IMEN-2020 and Modal Insan Fund (MI-2019-005). 


\section{REFERENCES}

Alford, T.L., Feldman, L.C. \& Mayer, J.W. 2007. Fundamentals of Nanoscale Film Analysis. Boston: Springer Science+Business Media, Inc. pp. 84-104.

Berhanuddin, D.D., Razak, N.E.A., Laurenco, B.Y., Majlis, B.Y. \& Homewood, K.P. 2019. G-Centre formation and behaviour in a silicon on insulator platform by carbon ion implantation and proton irradiation. Sains Malaysiana 48(6): 1251-1257.

Berhanuddin, D.D., Lourenço, M.A., Gwilliam, R.M. \& Homewood, K.P. 2017. The effect of temperature to the formation of optically active point-defect complex, the carbon G-centre in pre-amorphised and non-amorphised silicon. In IOP Conference Series: Materials Science and Engineering 384(1): 012062.

Berhanuddin, D.D., Lourenço, M.A., Jeynes, C., Milosavljević, M., Gwilliam, R.M. \& Homewood, K.P. 2012. Structural analysis of silicon co-implanted with carbon and high proton for the formation of the lasing G-centre. Journal of Applied Physics 112(10): 103110.

Biersack, J.P. 1981. Calculation of projected ranges - analytical solutions and a simple general algorithm. Nuclear Instruments and Methods 182-183(Part 1): 199-206.

Buckley, S.M., Tait, A.N., Moody, G., Primavera, B., Olson, S., Herman, J., Silverman, K.L., Rao, S.P., Nam, S.W., Mirin, R.P. \& Shainline, J.M. 2020. Optimization of photoluminescence from $\mathrm{w}$ centers in a silicon-on-insulator. Optic Express 28(11): 16057-16072.

Charnvanichborikarn, S., Villis, B.J., Johnson, B.C., WongLeung, J., McCallum, J.C., Williams, J.S. \& Jagadish, C. 2010. Effect of boron on interstitial-related luminescence centers in silicon. Applied Physics Letters 96(5): 051906.

Davies, G. 1989. The optical properties of luminescence centres in silicon. Physics Reports 176(3-4): 83-188.

Dee, C.F., Ahmad, I., Yan, L., Zhou, X. \& Majlis, B.Y. 2011. Amorphization of $\mathrm{ZnO}$ nanowires by proton beam irradiation. Nano 6(03): 259-263.

Gibbons, J.F. 1972. Ion implantation in semiconductor - part II: Damage production and annealing. In Proceeding of the IEEE 60(9): 1062-1096.

Husnain, G., Ahmad, I., Yao, S.D., Rafique, H.M., Umar, A.A. \& Dee, C.F. 2012. Depth-dependent tetragonal distortion study of AlGaN epilayer thin film using RBS and channeling technique. Modern Physics Letter B 26(14): 1250086.

Jahanshah, F., Sopian, K., Abdullah, H., Ahmad, I., Othman, M.Y. \& Zaidi, S.H. 2007. Investigation on ion implantation models impact on IV curve and thin film solar cell efficiency. In Proceedings of the $7^{\text {th }}$ WSEAS International Conference on Wavelet Analysis \& Multirate Systems. WSEAS. pp. 133137.

Nguyen, H.T., Phang, S.P., Wong-Leung, J. \& Macdonald, M. 2016. Photoluminescence excitation spectroscopy of diffused layers on crystalline silicon wafers. IEEE Journal of Photovoltaics 6(3): 746-753.

Rotem, E., Shainline, J.M. \& Xu, J.M. 2007. Electoluminescence of nanopatterned silicon with carbon implantation and solid phase epitaxial growth. Optic Express 15(21): 1409914106.

Rotem, E., Shainline, J.M. \& Xu, J.M. 2007. Enhanced photoluminescence from nanopatterned carbon-rich silicon grown by solid-phase epitaxy. Applied Physics Letters 91(5): 051127.

Schmidt, M.E., Zhang, X., Oshima, Y., Anh, L.T., Yasaka, A., Kanzaki, T., Muruganathan, M., Akabori, M., Shimoda, T. \& Mizuta, H. 2017. Interaction study of nitrogen ion beam with silicon. Journal of Vacuum Science \& Technology B, Nanotechnology and Microelectronics: Materials, Processing, Measuring, and Phenomena 35(3): 03D101.

Stoller, R.E., Toloczko, M.B., Was, G.S., Certain, A.G., Dwaraknath, S. \& Garner, F.A. 2013. On the use of SRIM for computing radiation damage exposure. Nuclear Instruments and Methods in Physics Research B: Beam Interactions with Materials and Atoms 310: 75-80.

Thabethe, T.T. 2014. Ion implantation in RBS Investigation of the diffusion of implanted Xenon in $6 \mathrm{H}-\mathrm{SiC}$. University of Pretoria. MS Thesis (Unpublished).

Webb, R. 2001. Surrey University Sputter Profile Resolution from Energy Deposition, SUSPRE. IBC, University of Surrey, United Kingdom.

Nurul Ellena Abdul Razak, Burhanuddin Yeop Majlis, Chang Fu Dee \& Dilla Duryha Berhanuddin* Institute of Microengineering and Nanoelectronics (IMEN)

Universiti Kebangsaan Malaysia

43600 UKM Bangi, Selangor Darul Ehsan

Malaysia

Morgan Madhuku

iThemba Laboratory for Accelerator Based Science (LABS)

Private Bag 11, Wits 2050 Johannesburg

South Africa

Ishaq Ahmad

NPU-NCP Joint International Research Center on Advanced Nanomaterials and Defects Engineering

National Centre for Physics

Islamabad 44000

Pakistan

*Corresponding author; email: dduryha@ukm.edu.my

Received: 20 July 2020

Accepted: 17 August 2020 